\title{
French participation in the International Equatorial Electrojet Year
}

At the Vancouver Assembly of IAGA in 1987, the Interdivisional Commission on Developing Countries (ICDC) supported the intensification of studies of the equatorial electrojet within the framework of the International Equatorial Electrojet Year (IEEY). This ambitious project was intended to stimulate the development of the interdisciplinary instrumentation and world-wide coverage necessary to study this ionospheric current system. The IEEY project has been coordinated by an International Scientific Committee, which also collaborates with other international programmes such as the World Ionosphere-Thermosphere Study (WITS), the Lower Thermosphere Coupling Study (LTCS), and the Solar-Terrestrial Energy Programme (STEP). Subsequently several French scientific groups and institutions (CEA, CNET, CNRS, IPGP, ORSTOM, and the Université Paris-Sud) joined the IEEY project, conducting either experimental campaigns to study the equatorial electrojet and related processes, or developing models and analytic studies. These groups then initiated collaborations with two African institutions, the University of Dakar in Senegal, and Abidjan University in the Ivory Coast.

During the IEEY many different instruments were operated in Africa, including

- a network of ten magneto-telluric stations from November 1992 to October 1994

- an ionosonde deployed at Korhogo in November 1992 in addition to the two permanent instruments at Dakar and Ouagadougou (Burkina Faso)

- an HF sounder deployed at Dakar

- an HF radar at Korhogo during two campaigns in 1993 and 1994

- a Fabry-Perot interferometer at Korhogo which has operated since November 1994

Analysis of the data obtained by these instruments has produced information on ionospheric phenomena on a wide range of scales, as indicated by the results presented in the seven papers of this special issue.

The data obtained by the magneto-telluric stations have been analysed to provide the parameters and the time variations of the equatorial electrojet considered as an ionospheric current ribbon. These measurements have allowed the characterisation of the variations of the induced electric field. By considering both quiet and disturbed magnetic situations, these data have demonstrated the existence of two different sources. On larger scales, the African magnetic data set has been used for global ionospheric modelling, demonstrating that mag- netic disturbance produced by auroral phenomena may extend to the planetary scale.

Fine-resolution observations by the three equatorial ionosondes have revealed small-scale structures in the daytime F2 peak, superposed on the slowly-varying $\ll$ trough $\gg$ distribution in the 5 degree magnetic latitude zone. The digital sounder has also allowed small-scale monitoring of the reflecting properties of the ionospheric plasma. Propagation channels have been analysed, both at long distances (Europe-Abidjan) and on monostatic modes around Dakar. The high resolution HF radar was also used to study daytime ionospheric structures during different magnetic conditions. In particular, it revealed small-scale instability processes up to the F-region peak.

Fabry-Perot interferometer profiles of the $630 \mathrm{mn}$ line have given continuous neutral wind velocity vectors at Korhogo during a dozen nights between November 1994 and March 1995. The altitude and maximum density of the F-layer peak measured simultaneously by the three ionosondes confirm the meridional wind control of the evening ionosphere.

In the Euro-African sector, the IEEY activities improved our knowledge of the aeronomy, electrodynamics, and physics of the equatorial ionospheric plasmas, as well as of the associated current circuit. Classical models of equatorial geophysics have been found to require some drastic revisions. The individuals involved in these studies during the IEEY are continuing to build an exceptional database, and are now looking for intervals where comparisons can be made with results obtained in other sectors, namely at Indian and South American longitudes.

Acknowledgements. The IEEY studies in the African sector were made possible by the participation of a large number of institutes. Funding was provided by the Ministère Français de la Coopération (Département de la Recherche et des Formations, and Département Télécommunications); ORSTOM (Département Terre Océan Atmosphère); CNET (France-Telecom Centre Lannion); the Ministère Français de la Recherche et de la Technologie; Centre National de la Recherche Scientifique (Département Sciences de l'Univers); the Centre à l'Energie Atomique; the Université ParisSud; Abidjan University, Ivory Coast; Dakar University, Senegal. We would like to express our deep gratitude to the many colleagues who have participated in the success of this experiment through their enormous personal commitment, to the Editorial Board of Annales Geophysicae and particularly to Sylviane Perret for producing this special issue.

Yves Cohen

Institut de Physique du Globe de Paris April 7, 1998. 